\title{
Testing Bifacial PV Cells in Symmetric and Asymmetric Concentrating CPC Collectors
}

\author{
Gomes João $^{1 *}$, Henrik Davidsson ${ }^{2}$, Gruffman Christian ${ }^{3}$, Maston Stefan ${ }^{3}$, Karlsson Björn ${ }^{4}$ \\ ${ }^{1}$ R\&D Department,Solarus Sunpower, Älvkarleby, Sweden \\ ${ }^{2}$ Energy and Building Design, Lund University, Lund, Sweden \\ ${ }^{3}$ Finsun AB, Älvkarleby, Sweden \\ ${ }^{4}$ Division of Energy Engineering, Mälardalen University, Västerås, Sweden \\ Email: *Joao.Gomes@ solarus.se
}

Received 2013

\begin{abstract}
Bifacial PV cells have the capacity to produce solar electricity from both sides and, thus, amongst other advantages, allow a significantly increase both in peak and annual power output while utilizing the same amount of silicone. According to the manufacturer, the bifacial cells are around 1.3 times more expensive than the single-sided cells. This way, bifacial PV cells can effectively reduce the cost of solar power for certain applications. Today, the most common application for these cells is in stationary vertical collectors which are exposed to sunlight from both sides, as the relative position of the sun changes throughout the day. Another possible application is to utilize these cells in concentrating collectors. Three test prototypes utilizing bifacial PV cells were built. The initial two prototypes were built for indoor testing and differed only in geometry of the reflector, one being asymmetric and the other symmetric. Both prototypes were evaluated in an indoor solar simulator. Both reflector designs yielded positive electrical performance results and similar efficiencies from both sides of the cell were achieved. However, lower fill factor than expected was achieved for both designs when compared to the single cell tests. The results are discussed and suggestions for further testing are presented. A third prototype was built in order to perform outdoor evaluations. This prototype utilized a bifacial PV cells string laminated in silicone enclosed between 2 standard glass panes and a collector box with an asymmetric CPC concentrator. The prototype peak electrical efficiency and temperature dependence were evaluated. A comparison between the performance of the bottom and top sides of the asymmetric collector is also presented. Additionally, the incidence modifier angle (IAM) is also briefly discussed.
\end{abstract}

Keywords: Bifacial PV Cells; Symmetric and Asymmetric Concentrating Concentrators; Reflector Geometry; Prototype; NOCT

\section{Introduction}

\subsection{The Use of Bifacial PV Cells in Collectors}

Photovoltaic (PV) cells are normally the most expensive component in solar panels [1].

Bifacial PV cells have the capacity to produce solar electricity from both sides. This way, these cells offer the possibility of significantly increasing both the peak and annual power output while utilizing the same amount of silicone during the cell production. This can lead to a lower material consumption per peak power produced and in turn a lower $\mathrm{kWh}$ cost.

Recent developments have allowed significant advances both in the technology of bifacial PV cells and on the production methods [2-4], thus allowing mass production and substantially lowering their production cost.

${ }^{*}$ Corresponding author.
According to the cell manufacturer, the price of one bifacial cell is around 1.3 times more expensive than the single- sided cells but, if each side receives the same annual solar radiation as a single cell, the output will be doubled.

Another important advantage is found during the collector manufacturing process. Bifacial PV cells can allow halving the number of cells that need to be soldered, thus doubling the capacity of the cell soldering machines which normally represent a big investment and a production capacity bottleneck for many collector manufacturers. For these reasons, bifacial PV cells can effectively reduce the cost of solar power for certain applications. However, the amount of radiation that each side of the bifacial cell sees differs considerably from application to application. Today, the most common application for these cells is in stationary vertical collectors which are exposed to sunlight from both sides, as the relative posi- 
tion of the sun changes throughout the day. These types of vertical installations take advantage of having a simplified cleaning process since most of the dirt falls to the ground by gravity. This can be a considerable advantage in desert areas that are prone to desert storms and lack access to water. However, in vertical applications, each side of the bifacial cell is far from yield its maximum potential, producing annually significantly less than a standard solar cell at tilt inclination.

Another possible application for bifacial PV cells is to utilize these cells in concentrating collectors where you can extract more annual power from each side of the cell while taking advantage of the cost reduction that concentration can provide. Still, concentrating PV collectors present several difficulties. PV cell efficiency can be reduced both by non-uniform light and due to the increase of temperature from concentration, although operating at slightly higher concentrations that $1 \mathrm{C}$ increases slightly the cell efficiency. This way, reflector shapes and normal operating cell temperature (NOCT) of the collector must be carefully considered during the design of these types of solar collectors.

Additionally, the annual output of a concentrating PV collector is strongly affected by the IAM.

\section{Method}

\subsection{Prototype Design}

Three test prototypes utilizing bifacial PV cells were built. All prototypes used the same string of bifacial PV cells. This string consisted in 37 cells connected in series. Each cell has a dimension of $26 * 148 \mathrm{~mm}$. Thus, the total cell area of the string is $0.14 \mathrm{~m}^{2}$.The string was enclosed between two glasses panes with standard glass transparency (often 85\%) for the initial prototype testing presented in this first paper. Future prototypes should be built using anti transparency glass like the glass cover of the box of third prototype. This glass cover is made of low iron glass with solar transmittance 0.95 at normal incidence angle according to the datasheets of the manufacturer.The reflectance of the aluminum reflectors used for all prototypes is $94 \%$ for the visible light spectra [5],according to the manufacturer datasheets.

The initial two prototypes for indoor measurements

The initial two prototypes were built for indoor testing and differed only in the collector box where the bifacial solar string was inserted. Both collector boxes had compound parabolic collectors (CPC) reflector but while the first was symmetric reflector the second was asymmetric.

Figure 1 shows the reflector shapes for both prototypes.

Reflector area was equal for all prototypes. The symmetric reflector concentrates 1,53 suns in each cell side while the asymmetric reflector receives 1 sun in the top side and 2,06 suns in the bottom side. Table 1 describes the areas and the concentration factors.

One of the reasons for testing both reflector shapes was to verify that the total cell output and other relevant parameters were identical. Even if the final concentration factor is the same for both prototypes, the light distribution on the cells is very different. These two prototypes were not inserted into a collector box and had no box glass cover.

Asymmetric prototype for outdoor measurements

The third prototype was inserted into a more robust collector box in order to be possible to perform outdoor measurements. Figure 2 shows the third prototype. This reflector design is patented by Solarus. A more detailed analysis geometry presented is present in the paper by Bernardo $R$. et al[6].

This prototype has bifacial PV cells laminated in silicone and enclosed between 2 glass panes. The average transparency of the silicone is $97 \%$ for the visible light, according to the manufacturer specifications. After testing the initial two prototypes, an asymmetric shape was selected for the reflector of the third prototype.

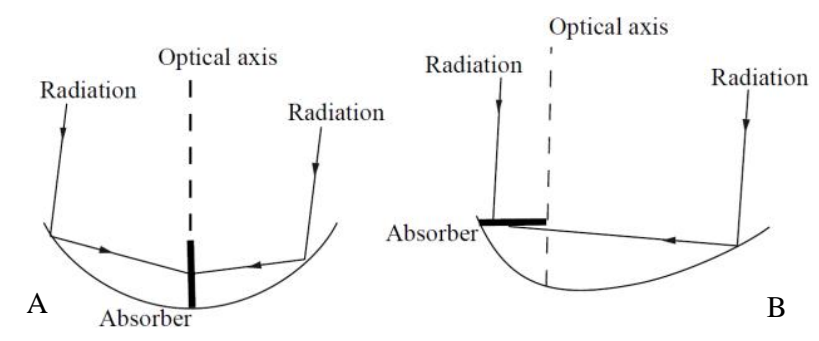

Figure 1. Reflector shape and optical axis of both asymmetric (B) and symmetric (A) prototypes.

Table 1. Areas and concentration factors of 2 bifacial concentrating collector design.

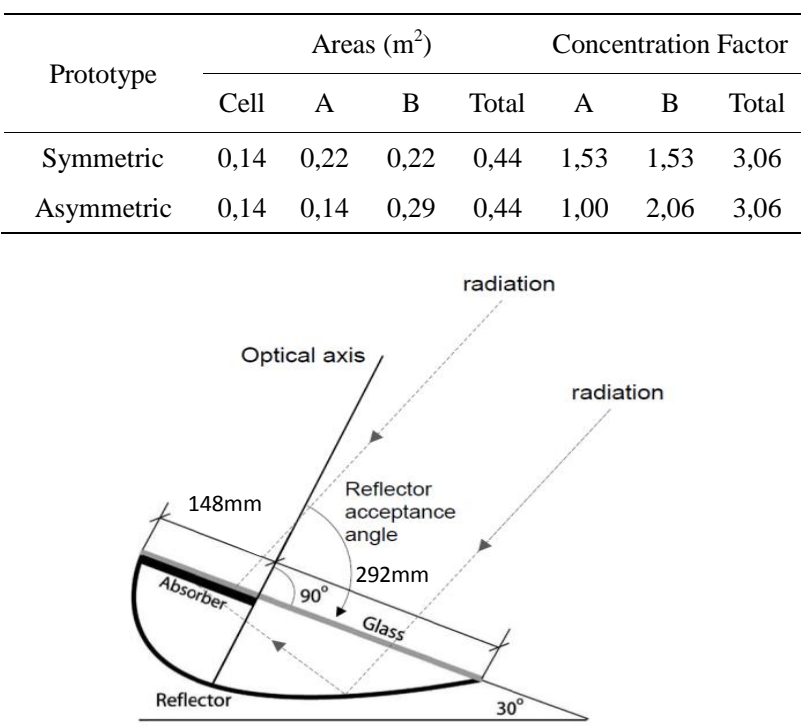

Figure 2. The geometry of the investigated bifacial PV prototype. 
In order to monitor cell temperature, a K-type sensor was installed inside the silicone in between the two glass panes in a location very close to the cells but without creating shading. Picture 1 shows the location of the K-type sensor.

The idea with the construction of the third prototype was to provide initial testing results before the construction of a full collector with the dimensions shown in Figure 3. This collector will have 38 series connected cut cells per string. The strings will be connected in parallel between them and also between receiver sides, as shown in Figure 3.

\subsection{Experimental Testing Setup}

The three collector prototypes were measured both indoors and outdoors. The electricity was measured using an IV tracer connected to a laptop. Data was retrieved from the IV tracer using software designed by Christian Gruffman at Finsun Inresol. This software is able to perform both single and continuous measurements. In the indoor measurement only the single measurement function was used while for the outdoor measurements both functions were utilized. The IV tracer draws an IV-curve based on 100 values at different currents and voltages, while the software retrieves this data and records the values of Imp, Isc, Vmp, Voc, Pmax, FF and cell efficiency. The electricity produced by the cells was not being continuously extracted during the measurements which may lead to cell overheating and consequent power reduction due to cell temperature dependence.

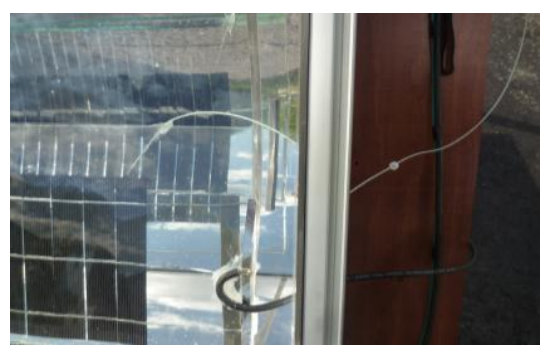

Picture 1.Location of the K-type sensor and aspect of the bifacial cell prototype.

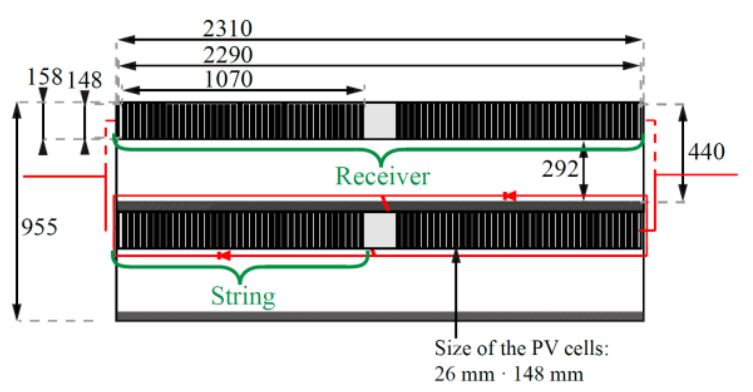

Figure 3.Top view of the future bifacial collector. The red lines show the electrical connections.

\section{Indoor test set-up}

The indoor solar simulator was designed to simulate solar radiation and consists of two rows of 8halogen light bulbs each with $1000 \mathrm{~W}$ of power. As in many solar simulators, the light distribution is the drawback, since it is far from perfect and it depends strongly on the position of the cells within the simulator. (Picture 2)

\section{Outdoor test set-up}

The outdoor set-up consisted in a tilt adjustable wooden stand where the collector was facing the sun. The selected tilt was the best for maximizing output for the location and the time of the year in which the measurements took place, March, May, June and July of 2011. Location was Älvkarleby, Sweden. Picture 3 shows the test set-up. The solar radiation was measured utilizing 3 sensors type SRS1000produced by the company Finsun Inresol. This pyranometer uses a sensing element made in a single crystal Si-cell. The output voltage is $100 \mathrm{mV}$ when exposed to $1000 \mathrm{~W} / \mathrm{m}^{2}$ solar radiation [8]. The 3 pyranometers mounted on the stand were calibrated against two other pyranometers. One of the 3 pyranometers was covered by a diffuser ring in order to obtain the diffuse radiation, as shown in Picture 3. Beam radiation is obtained by subtracting diffuse to global radiation.

In Picture 3, only the top reflector trough is related to the bifacial PV prototype. The bottom reflector trough contains a collector prototype of a PVT for another experiment and is not related to this paper.

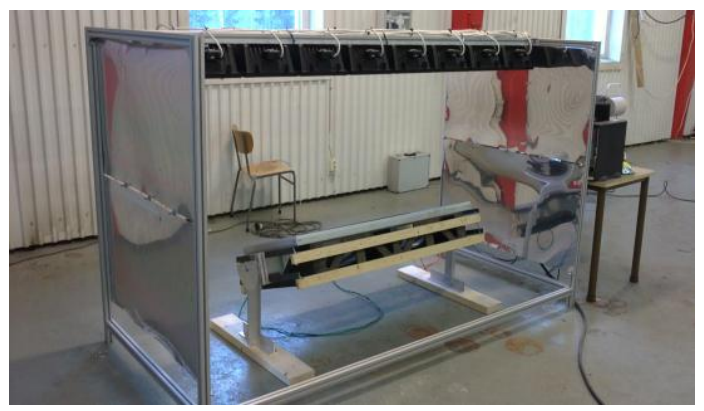

Picture 2.The solar simulator for the indoor measurements.

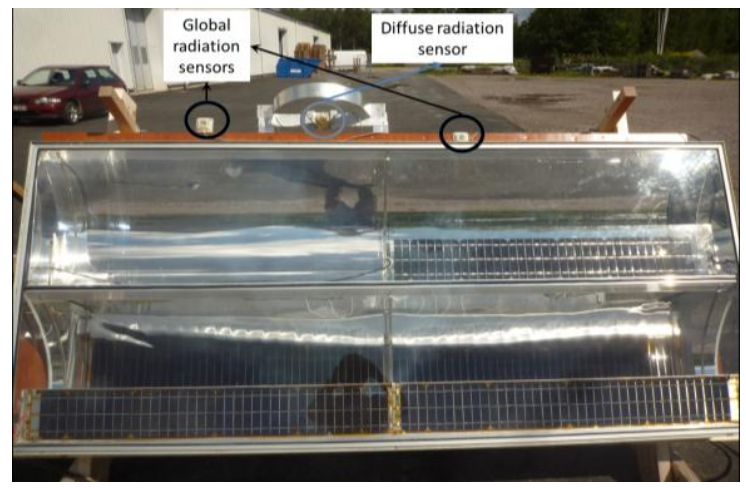

Picture 3.The measured bifacial collector (top trough) and the solar radiation sensors. 
Picture 4 shows the multimeter (Biltema Art. 15-275) that was prepared to read the cell temperature by connecting to the K-type wire shown in Picture 1.

\section{Results}

The two initial prototypes were evaluated in an indoor solar simulator.

\subsection{Indoor Results}

\section{Cell Evaluation}

The bifacial cells evaluated had a dimension of $156 \mathrm{~mm} * 156 \mathrm{~mm}$ which is also the standard market size for single side cells. These cells were tested and the results are presented in Table 2.

Since, concentrating the sunlight can cause current capability constrains that limit the collector output, actions were taken to reduce the current on the collector. This way, the bifacial cells were cut using a laser cell cutting machine that divided the cells into 6. Additionally, the cells were also cut $4 \mathrm{~mm}$ on each side to match the size of Solarus PVT collector cells and patented design. Thus, the cut cells have the dimensions of $148 \mathrm{~mm} * 26 \mathrm{~mm}$.In both cases, only one side of the bifacial cells was measured.

\section{Reflector design evaluation}

37 cut cells (dimension $26 * 148 \mathrm{~mm}$ ) were soldered togetherin series to form a string with an area of $0,142 \mathrm{~m}^{2}$.

This cell string was then inserted and tested under two different reflector configurations, one symmetric and one asymmetric. Table 3 describes the measuring results obtained.

Another obtained result was that the top part produced $44 \%$ of the total power, on the asymmetric design.

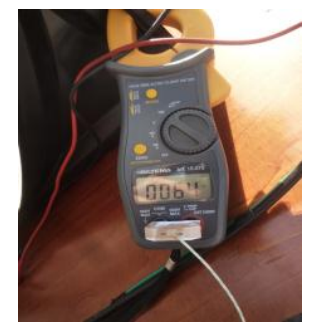

Picture 4.Multimeter measuring a cell temperature of $64^{\circ} \mathrm{C}$ in a sunny day with $28^{\circ} \mathrm{C}$ of outside temperature.

Table 2. Data for the 2 measured cells with different areas.

\begin{tabular}{cccccccccc}
\hline Type & Voc & Isc & Pmax & Vmp & Imp & FF & Area & Power In & Eff. \\
\hline A & 0,62 & 1,12 & $\mathbf{0 , 5 7}$ & 0,54 & 1,06 & 81,5 & 0,004 & 1050 & 14,13 \\
B & 0,63 & 6,15 & $\mathbf{3 , 0 4}$ & 0,53 & 5,71 & 78,0 & 0,024 & 900 & 13,86 \\
Units & V & A & W & V & A & $\%$ & $\mathrm{~m}^{2}$ & W/m & $\%$ \\
\hline
\end{tabular}

Notes: Type A - Cut cell; Type B - Standard Bifacial cell; Power In refers to the radiation that is hitting the cells; Eff. refers to efficiency.
Table 3. Results of 2 bifacial concentrating collector designs.

\begin{tabular}{cccccccccc}
\hline \multicolumn{10}{c}{ Asymmetric } \\
\hline Side & Voc & Isc & Pmax & Vmp & Imp & FF & P. In & Area & Eff. \\
Both & 22,9 & 4,1 & 60,3 & 17,6 & 3,4 & 64,2 & 1200 & 0,44 & 11,5 \\
Bottom & 22,3 & 2,4 & 33,9 & 17,7 & 1,9 & 63,0 & 1100 & 0,29 & 10,5 \\
Top & 22,5 & 1,9 & 27,0 & 18,2 & 1,6 & 68,0 & 1600 & 0,14 & 11,9 \\
\multicolumn{1}{c}{ Symmetric } \\
Side & Voc & Isc & Pmax & Vmp & Imp & FF & P. In & Area & Eff. \\
Left & 22,3 & 1,8 & 25,5 & 18,5 & 1,4 & 63,6 & 1100 & 0,22 & 10,7 \\
Right & 22,4 & 1,7 & 24,9 & 18,5 & 1,3 & 65,1 & 1100 & 0,22 & 10,4 \\
Both & 22,9 & 3,4 & 49,5 & 18,8 & 2,6 & 63,6 & 1100 & 0,44 & 10,3 \\
Units & V & A & W & V & A & $\%$ & W/m & $\mathrm{m}^{2}$ & $\%$ \\
\hline
\end{tabular}

\subsection{Outdoor Results}

The collector was measured outside in 2 different occasions.

Preliminary Testing - March 2012:

For a standard flat plate collector, the best tilt corresponds to $90^{\circ}$ minus the projected solar altitude for the specific location and time of the year. As detailed in the paper from Bernardo $R$. et al [6,7], for this specific asymmetric geometry the best tilt suffers a deviation from the best tilt of a standard flat plate by $5^{\circ}$ to $10^{\circ}$ in the direction. The best entrance angle for the radiation is also shown by the radiation arrows in Figure 2.

The collector was measured outside for about one hour between $11 \mathrm{~h} 20$ and $12 \mathrm{~h} 20$. This period had extremely stable weather conditions during which regular radiation measurements were recorded manually.

At this time, no equipment was available to monitor the changes in cell temperature and the only available information was that the initial cell temperature was equal to outdoor temperature of $0^{\circ} \mathrm{C}$. Assuming standard temperature dependence from literature of $0,5 \% /{ }^{\circ} \mathrm{K}$ [9] and assuming that $\mathrm{P}_{\max }$ has to remain stable when adjusted by the above coefficient to the reference temperature of $25^{\circ} \mathrm{C}$, a temperature curve was linearly estimated. Figure 4 shows the measured values of $\mathrm{P}_{\max }$ and efficiency over time as well as an estimation of cell temperature, $\mathrm{P}_{\max }$ at $25^{\circ} \mathrm{C}$ and efficiency at $25^{\circ} \mathrm{C}$.

Table 4 presents a comparison between the bottom and both sides of the prototype. All data is measured with the exception of the temperature that is estimated. The 2 measurement (bottom and both) were done within $7 \mathrm{sec}-$ onds. Table 5 presents the same comparison for the estimated values at $25^{\circ} \mathrm{C}$. Bottom side represents $55 \%$ of the total power of the string.

\section{June 2012 Testing}

New measurements on the bifacial prototype were done when Solarus solar laboratory gained the capacity to $\log$ the radiation and measure cell temperature. Figure 
5 plots the global radiation in Älvkarleby on the $22^{\text {nd }}$ of June. The tilt was the most adequate for maximizing the output for this collector at this latitude and time of year.

$\mathrm{V}_{\mathrm{mp}}, \mathrm{I}_{\mathrm{sc}}, \mathrm{P}_{\max }$ and cell temperature are shown in the Figure 6.

The cell temperature was taken at 6 different times and then extrapolated using a $3^{\text {rd }}$ order polynomial equation matching the measured data with an $\mathrm{R}^{2}$ of 0,999 . Highest measured cell temperature was $88^{\circ} \mathrm{C}$ at $14 \mathrm{~h} 30$ after constant perfect radiation day with an ambient temperature of $32^{\circ} \mathrm{C}$.

Figure 7 shows the measured electrical efficiency dependence on cell temperature expressed both in total area and cell area. The dependence of electrical efficiency on temperature is $-0.51 \% / \mathrm{K}$.

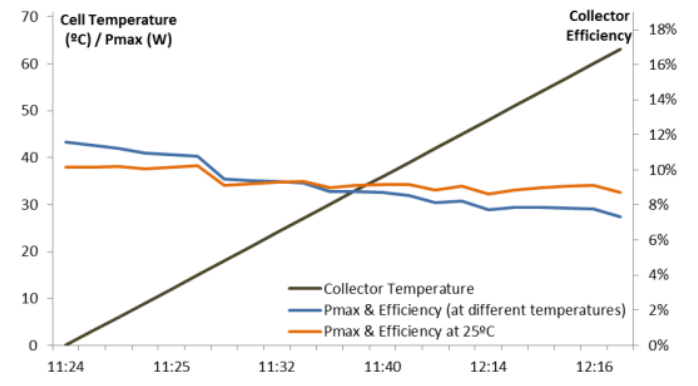

Figure 4. Pmax and efficiency over time (measured at a temperature represented by $T$ curve); Pmax and efficiency at $25^{\circ} \mathrm{C}$ (estimated)and cell temperature.

Table 4. Comparison bottom vs both sides at $36^{\circ} \mathrm{C}$.

\begin{tabular}{ccccccc}
\hline Side & Voc & Isc & Vmp & Imp & FF & \\
\cline { 1 - 5 } Bottom & $18,1 \mathrm{~V}$ & $1,7 \mathrm{~A}$ & $13,3 \mathrm{~V}$ & $1,4 \mathrm{~A}$ & $57,8 \%$ & \\
Both & $18,9 \mathrm{~V}$ & $2,9 \mathrm{~A}$ & $13,9 \mathrm{~V}$ & $2,3 \mathrm{~A}$ & $58,5 \%$ & \\
Side & Cell T. & Pmax & Eff/Total area & Eff/Cell area \\
Bottom & $36^{\circ} \mathrm{C}$ & $18,0 \mathrm{~W}$ & $7,2 \%$ & $14,9 \%$ \\
Both & $36^{\circ} \mathrm{C}$ & $32,5 \mathrm{~W}$ & $8,8 \%$ & $13,4 \%$ \\
\hline
\end{tabular}

Table 5. Comparison bottom vs both sides at $25^{\circ} \mathrm{C}$.

\begin{tabular}{ccccc}
\hline Side & Cell T. & Pmax & Eff/Total area & Eff/Cell area \\
\hline Bottom & $25^{\circ} \mathrm{C}$ & $19,0 \mathrm{~W}$ & $7,6 \%$ & $15,6 \%$ \\
Both & $25^{\circ} \mathrm{C}$ & $34,3 \mathrm{~W}$ & $9,2 \%$ & $14,1 \%$ \\
\hline
\end{tabular}

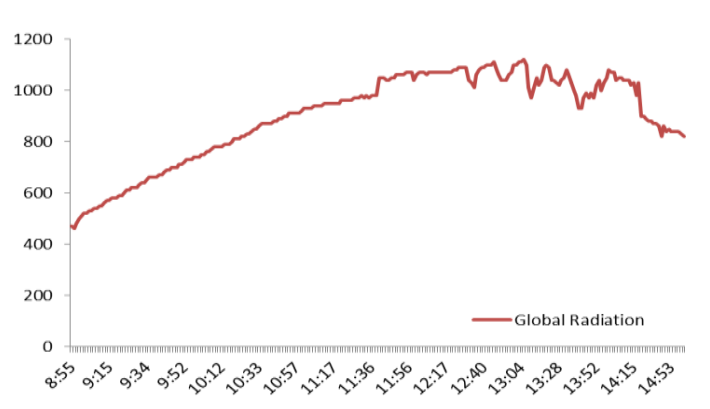

Figure 5. Global radiation on $22^{\text {th }}$ of June of 2012.

\section{Conclusions}

\subsection{Indoor Testing}

\section{Cell Evaluation}

Two sizes of cells were evaluated. As expected, a smaller cell size presented a higher FF even when exposed to a high radiation level and thus a slightly higher efficiency.

The value of $14 \%$ efficiency from the manufacturer was confirmed. The cell manufacturer stated that these efficiencies will be raised in the near future to significantly higher levels.

\section{Reflector design evaluation}

Both geometries yielded similar results in terms of FF, efficiency and $\mathrm{V}_{\mathrm{oc}}$. The difference in proximity to the light source due to the asymmetric reflector led to different light intensities which in turn lead to different Isc, Imp and Pmax. Nevertheless, these values remain consistent. However, a significant decrease in FF and cell efficiency was observed for both geometries when compared to the single side cell testing. While the single cell shows a FF of $80 \%$ and an efficiency of $14 \%$, the string measurements for both geometries shows a FF of $65 \%$ and around $11 \%$ of efficiency. This decrease is due to the losses from the reflector reflectance and possibly a current capability constrains may also occur due to the concentration of light. Additionally, at least a part of the decrease can also be attributed to non-uniform cell distribution from the solar simulator and thus further outdoor testing is required.

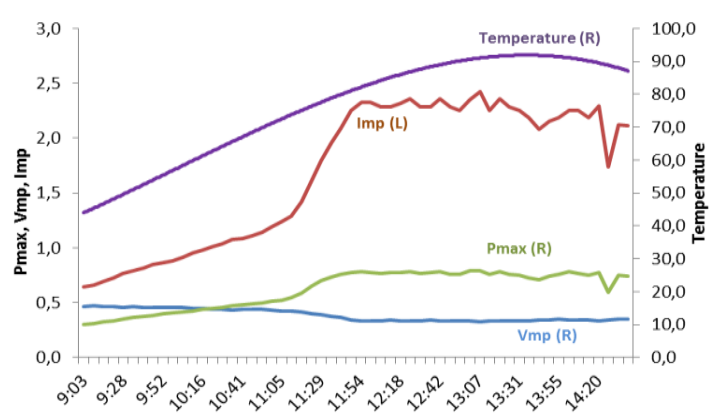

Figure 6. $P_{\text {max }}, I_{m p}, V_{m p}$ and cell temperature for the day of $22^{\text {th }}$ of June. The (R) and (L) symbolizes right or left axis.

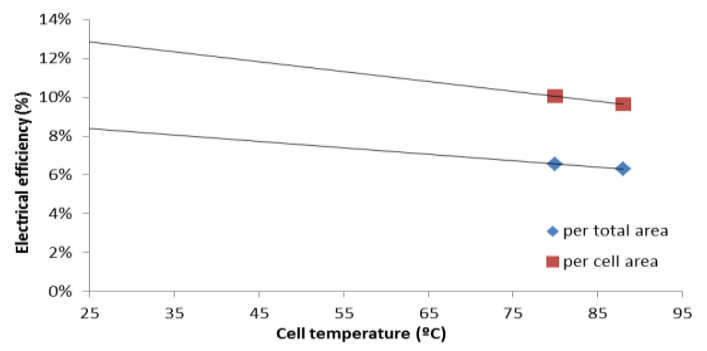

Figure 7. Electrical efficiency dependence on cell temperature - measured 
The Solarus PVT reflector geometry was selected for outdoor testing both for practical reasons and since there were no relevant constrains verified during this step. Current capability seems to be equal for both designs since FF is similar. Thus another conclusion is that the side of the solar cell from where the current is flowing into the busbar does not impact the current capability.

In the asymmetric reflector geometry, the top part was producing $44 \%$ of the total power. Since top part represents $33 \%$ of the area, it should produce also $33 \%$ of the power, if there were no losses due to reflector reflection. This decrease is again due to the reflector losses and non-uniform light distribution. Additionally, it is important to notice that the solar simulator gives more than $1000 \mathrm{w} / \mathrm{m}^{2}$ and that its radiation spectra is not equal to the solar radiation which further motivates performing outdoor testing.

\subsection{Outdoor Testing}

Bottom side represents $55 \%$ of the total power of the string which is consistent with the indoor testing. This is below the theoretical maximum and can be improved. The obtained FF values seem to imply that there is a current capability constrain. $58 \%$ outdoor and $64 \%$ indoors are low values in comparison to standard PV modules, according to literature [9]. At $36^{\circ} \mathrm{C}, \mathrm{I}_{\mathrm{mp}} / \mathrm{I}_{\mathrm{sc}}$ is 0,83 while $\mathrm{Vmp} / \mathrm{Voc}$ is 0,72 signaling that shunt resistance is more significant than series resistance. As expected, the bottom side presents a higher efficiency per cell area due to the concentration factor of 2 while a lower efficiency per total area due to the extra losses with reflector reflectance.

The dependence of electrical efficiency on temperature is $-0.51 \% / \mathrm{K}$, in good agreement with the common value for solar cells described in literature [9].

At $25^{\circ} \mathrm{C}$ and $1000 \mathrm{w} / \mathrm{m}^{2}$, the electrical efficiency expressed per total area is $8,4 \%$. If expressed per cell area, this value is $12,9 \%$.

The IAM is an important parameter for any non-track$\mathrm{g}$ concentrating collector and for the asymmetric bifacial PV as well. Figure 6 shows that for bifacial PV, an output increase starts at $11 \mathrm{~h} 30$ under steady weather conditions. Comparing to the PVT measured Bernardo R. et al [6], the tested bifacial PV has a bigger time period unaffected by shading since the string is one cell smaller and closer to the center, the prototype. The afore mentioned

\section{Nomenclature}

CPC
IAM
NOCT
IV Curve
I $_{\mathrm{mp}}$

Compound Parabolic Collector
Incidence Angle Modifier
Normal Operating Cell Temperature
Current and Voltage Curve
Maximum Power Current

figure also shows how the voltage drops in the bifacial PV prototype with the temperature increase.

Since the crystalline solar cells are translucid, it was expected that the solar radiation would go through the cells and that high operating cell temperature would not be reached. However, this did not happen. It is recommended that a new prototype is built where: 1) Only anti reflectance glasses are used. 2) Placing the absorber in contact with the top glass should have a big increase impact in NOCT of the collector by greatly increasing the heat losses.

\section{REFERENCES}

[1] International Renewable Energy Agency, "Renewable Energy Technologies: Cost Analysis Series - Solar Photovoltaic", Volume 1: Power Sector Issue 4/5, June 2012.

[2] A. Kränzl, R. Kopecek, K. Peter, P. Fath "Bifacial Solar Cells on Multi-Crystalline Silicon with Boron BSF and Open Rear Contact". Proceedings of the $4^{\text {th }}$ World Conference on Photovoltaic Energy Conversion. May 2006 Vol. 1, pp $968-971$.

[3] V. D. Mihailetchi et al. "Screen Printed N-Type Silicon Solar Cells for Industrial Applications". 25th European Photovoltaic Solar Energy Conference and Exhibition, 6-10 September 2010, Valencia, Spain DOI: $10.4229 / 25$ thEUPVSEC2010-2DO.2.2

[4] C. Duran et al. "Bifacial Solar Cells with Selective B-BSF by Laser Doping". 24th European Photovoltaic Solar Energy Conference, 21-25 September 2009, Hamburg, Germany.

DOI: 10.4229/24thEUPVSEC2009-2CV.5.19

[5] Alanod, reflector manufacturer, 2012. http://alanod.com.

[6] Bernardo R. et al., "Measurements of the Electrical Incidence Angle Modifiers of an Asymmetrical Photovoltaic/ Thermal Compound Parabolic Concentrating-Collector," Power and Energy Engineering Conferenceand Engineering, Sanya, China, Dec 31, 2012 - Jan 2, 2013, unpublished

[7] Bernardo, L.R et al. Performance evaluation of low concentrating photovoltaic/thermal systems: A case study from Sweden. Solar Energy2011, 85, 1499-1510

[8] N. Gentile et al., "Construction of a small scale laboratory for solar collectors and solar cells in a developing country", Power and Energy Engineering Conferenceand Engineering, Sanya, China, Dec 31, 2012 - Jan 2, 2013, unpublished

[9] S. Wenham et al, "Applied Photovoltaics", $2^{\text {nd }}$ edition, Earthscan, London, 2007, ISBN 978-1844074013.

$\mathrm{I}_{\mathrm{sc}}$
$\mathrm{V}_{\mathrm{mp}}$
$\mathrm{V}_{\mathrm{oc}}$
$\mathrm{P}_{\max }$
$\mathrm{FF}$

Short Circuit Current
Maximum Power Voltage
Open Circuit Voltage
Maximum Power
Fill Factor

(A) 